Employee of: Regeneron, A. Boyapati Shareholder of: Regeneron Pharmaceuticals, Employee of: Regeneron Pharmaceuticals, C. Xu Shareholder of: Sanofi, Employee of: Sanofi

DOI: 10.1136/annrheumdis-2018-eular.1375

\section{AB0473 IMMUNOGENICITY OF BIOSIMILARS FOR RHEUMATIC DISEASES: AN UPDATED REVIEW FROM REGULATORY DOCUMENTS AND CONFIRMATORY CLINICAL TRIALS}

V. Strand ${ }^{1}$, J. Goncalves ${ }^{2}$, T.P. Hickling ${ }^{3}$, H. Jones ${ }^{4}$, L. Marshall ${ }^{4}$, J. Isaacs ${ }^{5}$. ${ }^{1}$ Stanford University School of Medicine, Palo Alto CA, USA; ${ }^{2}$ iMed-Research Institute for Medicines, Faculdade de Farmácia da Universidade de Lisboa, Lisboa, Portugal; ${ }^{3}$ Biomedicine Design, Pfizer, Andover, MA; ${ }^{4}$ Inflammation and Immunology, Pfizer, Collegeville, PA, USA; ${ }^{5}$ NIHR Newcastle Biomedical Research Centre, Newcastle upon Tyne Hospitals NHS Foundation Trust and Newcastle University, Newcastle upon Tyne, UK

Background: Several biosimilars have been approved for the treatment of rheumatic diseases by the European Medicines Agency (EMA) or the US Food and Drug Administration (FDA).

Objectives: To summarise immunogenicity data from regulatory documents or confirmatory trials of biosimilars approved by the EMA or FDA for the treatment of rheumatic diseases.

Methods: EMA Public Assessment Reports (EPARs), FDA Clinical Summaries, PubMed records, and EULAR and ACR abstracts were searched for immunogenicity data from confirmatory trials of approved TNF $\alpha$ or CD20 inhibitor biosimilars in patients with rheumatic diseases. Data collected included the proportion (\%) of patients positive for anti-drug antibodies (ADAbs) among all patients and the proportion (\%) of patients with neutralising antibodies (nAbs) among ADAb-positive patients.

Results: We identified 10 biosimilars approved by the EMA or FDA: three each for adalimumab (BI 695501, SB5, and ABP 501) and infliximab (SB2, CT-P13, and infliximab-qbtx) and two each for etanercept (GP2015 and SB4) and rituximab (CT-P10 and GP2013). The duration of treatment periods in the 16 identified trials (which varied in design and methodology of $A D A b / n A b$ detection) ranged from 12 weeks to 102 weeks. Across treatment groups in all trials, $0 \%$ to $62 \%$ of patients were ADAb-positive, of whom $0 \%$ to $100 \%$ were also nAb-positive. The lowest proportions of ADAb-positive ( $0 \%-13 \%)$ and nAb-positive patients $(0 \%-3 \%)$ were observed in the trials of etanercept and its biosimilars, and the highest in the trials of infliximab and its biosimilars (ADAbs: $20 \%-62 \%$; nAbs: $88 \%-100 \%$ ). Consistent with the biosimilar designation, the proportions of ADAb- and nAb-positive patients in individual trials were similar between the originator and biosimilar products. Of note, in a 52 week trial of etanercept and its biosimilar SB4, the incidence of ADAs by Week 52 was significantly lower with SB4 than with etanercept (1\% [3/ $299]$ vs $13 \%$ [39/296], p < 0.001). However, as noted in the SB4 EPAR, this difference, which was not reflected in the incidence of nAbs and efficacy or safety of etanercept, may have been due to an ADAb assay bias in samples collected at Weeks 4 and 8, when 37/39 ADAbs in the etanercept group and 2/3 in the SB4 group were detected.

Conclusions: Immunogenicity of the approved biosimilars is generally similar to that of originator products. For ETN, which has been associated with relatively low
$A D A b$ levels, there was a discrepancy in ADAb incidence compared with its biosimilar SB4, but those differences were transient and did not affect clinical activity or safety.

Acknowledgements: Sponsored by Pfizer Inc.

Disclosure of Interest: V. Strand Consultant for: AbbVie, Amgen, AstraZeneca, Bristol-Myers Squibb, Boehringer Ingelheim, Celgene, Celltrion, Corrona, Crescendo, EMD Serono, Genentech/Roche, GSK, Janssen, Eli Lilly, Merck, Novartis, Pfizer, Regeneron, Samsung, Sandoz, Sanofi, and UCB, J. Goncalves: None declared, T. Hickling Shareholder of: Pfizer, Employee of: Pfizer, H. Jones Shareholder of: Pfizer, Employee of: Pfizer, L. Marshall Shareholder of: Pfizer Employee of: Pfizer, J. Isaacs Grant/research support from: Pfizer, Roche, Consultant for: Pfizer, Abbvie, Janssen, Roche, Speakers bureau: Pfizer, Abbvie, Roche

DOI: 10.1136/annrheumdis-2018-eular.3076

\section{AB0474 THE CLINICAL EFFECTIVENESS AND COST SAVINGS OF TAPERING BIOLOGIC DMARDS IN PATIENTS WITH INFLAMMATORY ARTHRITIS AT A UK DISTRICT GENERAL HOSPITAL}

W.P. Lee, R. Manhas, V. Sebbage, S. Kyle. Rheumatology, North Devon District Hospital, Barnstaple, UK

Background: Biologic DMARDs (bDMARDs) have led to substantial improvement in clinical outcomes for treatment of rheumatoid arthritis (RA), psoriatic arthritis (PsA) and axial/peripheral spondyarthropathy(SpA), making remission a realistic target. Current guidelines suggest clinicians should consider tapering after achieving remission in RA. ${ }^{1}$ Nevertheless, the optimal approach for tapering bDMARDs remains unknown and un-standardised across conditions. ${ }^{2}$

Objectives: To evaluate the tapering strategies on 3 major rheumatological disease entities (RA, PsA, SpA), the number of patients successfully tapered and the total cost saving from successful tapering.

Methods: The study was conducted at North Devon District Hospital in Barnstaple, UK and includes all bDMARDs users up until 31st December 2017. The tapering strategy was identified from hospital notes. Patients who are deceased, lost to follow-up or discontinued bDAMRDs due to contraindication or adverse effects were excluded. Successful tapering is defined as patient on tapered dose or had their biologics withdrawn and remains at target treatment level (RA: DAS- $28<2.6$ PsA: $<3$ tender joints and $<3$ swollen joints; SpA: BASDAI $<4$ ).

Results: There are a total of 298 patients: 174 RA; 59 PsA; 57 SpA; 8 other diag noses. 94 patients (31.5\%) had attempted tapering: 52 RA, 18 PsA, 22 SpA. 60 (20.1\%) successfully tapered their bDMARDs: 34 RA (56.7\%); 13 PsA (21.7\%); $13 \mathrm{SpA}(21.7 \%)$. Out of $34 \mathrm{RA}, 30$ seropositive; 4 seronegative; 24 co-prescribed with synthetic DMARDs, 10 on monotherapy. Out of $13 \mathrm{PsA}, 8$ co-prescribed with synthetic DMARDs; 5 on monotherapy.

59 tapered by increasing interval of subcutaneous treatment. Only 1 RA patient tapered its IV dose of tocilizumab. This patient is excluded from the final analysis. Tapering of subcut bDAMRDs therapy by disease and price (table 1). Number rounded to 2 decimal points.

\begin{tabular}{|c|c|c|c|c|c|c|c|c|c|}
\hline Disease & bDAMRDs & $\begin{array}{c}\text { No. of } \\
\text { patients }\end{array}$ & $\begin{array}{l}\text { Usual dose of } \\
\text { interval (days) }\end{array}$ & $\begin{array}{l}\text { Mean tapered dose } \\
\text { interval (days) }\end{array}$ & $\begin{array}{c}\text { Mean period of } \\
\text { tapering } \\
\text { (months) }\end{array}$ & $\begin{array}{l}\% \text { saving per unit } \\
\text { biologic }\end{array}$ & $\begin{array}{l}\text { Cost per unit } \\
\text { biologic }(£)\end{array}$ & $\begin{array}{c}\text { Cost Saving per } \\
\text { patient }(£)\end{array}$ & $\begin{array}{l}\text { Total cost } \\
\text { saving(£) }\end{array}$ \\
\hline \multirow[t]{4}{*}{ RA } & $A D A$ & 12 & 14 & 7.00 & 27.75 & 50.00 & 352.14 & 9771.89 & 117262.68 \\
\hline & CZP & 13 & 14 & 6.85 & 22.92 & 48.92 & 357.50 & 8016.92 & 10421.96 \\
\hline & ETN & 5 & 7 & 8.20 & 34.40 & 117.14 & 134.06 & 21608.41 & 108042.05 \\
\hline & TOC & 3 & 14 & 3.00 & 14.75 & 42.86 & 179.20 & 4531.50 & 13594.50 \\
\hline Total & & 33 & & & & & & & 249321.19 \\
\hline \multirow[t]{3}{*}{ PsA } & $A D A$ & 7 & 14 & 3.14 & 14.86 & 22.43 & 352.14 & 2347.43 & 16432.01 \\
\hline & GOL & 4 & 28 & 10.50 & 18.25 & 28.57 & 701.93 & 4803.83 & 19215.32 \\
\hline & ETN & 2 & 7 & 2.00 & 11.50 & 28.57 & 134.06 & 1761.84 & 3523.68 \\
\hline Total & & 13 & & & & & & & 39171.01 \\
\hline \multirow[t]{4}{*}{ SpA } & $A D A$ & 9 & 14 & 4.89 & 20.30 & 34.93 & 352.14 & 4993.90 & 44945.10 \\
\hline & GOL & 2 & 28 & 10.50 & 5.63 & 37.50 & 701.93 & 7121.81 & 14243.62 \\
\hline & CZP & 1 & 14 & 10.00 & 10.00 & 71.43 & 357.50 & 5107.25 & 5107.25 \\
\hline & ETN & 1 & 7 & 3.00 & 31.00 & 42.86 & 134.06 & 7124.81 & 7124.81 \\
\hline Total & & 13 & & & & & & & 71420.78 \\
\hline Grand & & 59 & & & & & & & 359912.98 \\
\hline
\end{tabular}

ADA - adalimumab; TOC - tocilizumab; ETN - etanercept; GOL - golimumab; CZP - certolizumab pegol

Conclusions: In our study, $20 \%$ of bDAMRDs users successfully tapered their dose. The total cost saving is significant at £359,912.98 over the tapered period, of which $£ 249,321.19(69 \%)$ in RA; $£ 39,171.01(11 \%)$ in PsA; $£ 71,420.78(20 \%)$ in SpA. 